\title{
PREVENTORIA
}

\section{A Symposium on the Care of the Children of Leprous Parents}

\section{Introduction by the Editor}

It is generally accepted as a fact that children separated from leprous parents at birth and kept away from infection will not contract leprosy. Another accepted fact is that children are more susceptible to leprosy than adults.

From the prophylactic standpoint these two facts indicate how important it is that lepers, especially those with open lesions, should not have children, and if they do that the children should be removed at birth and kept away from infection. Also if isolation has not been carried out at birth it should take place as soon as possible, since continued superinfection may break down resis-tance which a slighter degree of infection would not have done.

To prevent the birth of children is a difficult matter. In the institutions of India and many other countries the sexes are segregated. In Korea and elsewhere sterilization of the male has been resorted to. In democratic countries this latter method must be voluntary and therefore of limited scope. Also in Roman Catholic countries it is forbidden by the tenets of the Church.

There are three possible ways of separating the child and infeitious parent. to remove the patient leaving the child to be looked after by relatives or in an institution; to remove the child; to remove both patient and child, the former to a leprosarium and the latter to a preventorium. If the child can be looked after adequately"at home it is better that it should stay there in its natural surroundings, to which restoration may be difficult once the links have been broken.

Preventoria are of two main kinds, the crèche in which the child is looked after till it is two or three years old, after which it is sent to relatives, and the dormitory in which children are kept till 
they reach the years of uscfulness, or even longer tilt they have learned some useful trade or other employment.

In India the latter type of preventorium is most common under the care of Missions. Due to the segregation of the sexes chil dren are seldom born in these institutions, but patients often come with young children and admission of the adult implies care of the child. In a typical Indian institution ther

dren's quarters : for those with definite ieprosy, for those under observation and with closed lesions, and for those children of leper parents who show no signs of the disease.

In Brazil, a comparatively wealthy country with a large but limited amount of leprosy and a fairly high standard of living, the provision of preventoria on an adequate scale is not so difficult. The stigma of leprosy often makes relatives refuse to take care of the children of lepers. In 1940 there were 13,500 interned lepers and it was hoped soon to have twice that number. There are 22 preventoria with over 2,500 children. The newest of these are on up-to-date lines with a nursery for infants, a dormitory for children from two to ten and clormitories for older boys and girls. There are schools and arrangements for vocational training. Buildings are separate and joined by covered porches where children can play on rainy days.

In Nige

plexing one. There is not as a rule too strong an objection by relatives to taking care of children, at least after the first two or three years of age period, but if they find willingness on the part of Mission or Government institutions to take their children they like to take advantage of it. It has been found in many cases that children whe have been brought "1p) on milk, patent foods and other delicacies in an institution are unable to stand, the rougher village: life later and tend to die off when returned to their relatives Nigeria is a poor country and, though the Government is spending large sums of money on leprosy control, the support of healthy' children of lepers in large numbers from birth to manhood wouid involve an expense heavier than the exchequer could stand. The most serious difficulty is where patients have been isolated by their clans in small communities outside the villages. This is in line with the policy adopted and makes it possible to carry out segregation on a much cheaper and therefore larger scale than if all have to be admitted to in

vision it is possible to keep these patients from mixing with the healthy villagers, but it is much more difficult to prevent small children from mixing with their leprous relatives.

The problem is lessened if isolation is applicd only to open 
cases. It has been suggested that children of open cases should, after weaning, be placed uncler the care of closerl fomale cases; here however another danger arises, for it is difficult to liecp) children anywhere inside an institution without their coming in contact with open cases.

Apart from expense, the rumning of a jreventorium, an! especially of a crèche, requires very careful and sk and it is not always easy to obtain the necessary staff.

The general principles for guidance are the following :-

(1) It is of paramount importance to keep children from contact with open cases from birth onwarls.

(2) A determined effort shouid be made to lodge children with relatives either from birth or, failing that, from the end of infancy, the carly period being spent in a well-run crèche. This is on the condition that the child is well looked after and kept from? contact with infection.

(3) A crèche or preventorium badly run or insufficiently supervised is worse than none at all.

Copies of this introduction were sent to several leprosy workers asking for comments. The following contributions have been received. A previously published article by I)r. I owe relevant to this subject is also added. The editor zeill zeclicume furthey correspondence on this very important matter.

\section{Comments on the above by [)r. T. D. F. Money, Senior Leprosy' Control Officer, Nigeria.}

I should put the reason for closed cases not having children on the ground that pregnancy may exacerbate the lisease. I incline to the view that closed cases are not langerous even Io infants at the breast.

It is, I think, important to stress not only the benefit to the child of being brought up in the family, provided this is in other ways satisfactory, but also the responsibility of relations in these matters. This is great and the tendency is strong in some places to thrust on the state, or voluntary bodies, not nnly the care of the leprous patient, but as many of the related problems as possible, and, I believe, this needs careful watching.

I think mention should be made of the difficulties of rearmg children, especially in a hot climate, by artificial methods in th absence of nursing staff up) to S.R.N. standarils, steam sterilization laid con, etc. The danger of cross infection is high and the results disastrous. It is of interest to note that in the latest hospitals in England provision for infants takes the form of placing cach 
sefarately in what amounts virlually to a glass tule. In a word the artificial rearing of infants demands standards of skill and equipment which are not in sight except in atvancel countries.

1 agree with the point about the dangers, on return of the artificially reared infant to its family in primitive conditions. Shoukl infants in a "preventorsum" be protected from material infection, or the risk be taken in allowing the possible development of an immunity against almost certain infection later?

$\Lambda$ outstanding difficulty has been touched on in the use of the segregation village as a measure of prevention.

I favour prior concentration on the segregation of mothers who, having chil!!ren, are open cases. I entirely agree with your summary of principles.

Fiurther olservations are :-

(a) In rearing unweaned infant in the absence of first-class facilities for artificial methods, wet-nursing calls for consideration, preferably by a relative, possibly by a closed case. In some places there is strong prejudice against wet-nursing as such. If wet-nursing is impracticable, placing the infant with a mother who is a closed case, to live with her may be considered. In this event the artificial food is issued to her either prepared, or unprepared, and a health visitor gives general supervision both in the home and through an infant welfare clinic.

(b) Weaned children who have not been placed with relations, but for whom care must be arranged, may be placed with mothers who are closed cases. These mothers may then live in a settlement in a special reserve from which open cases are excluded, or in an associated (for convenience of administration, staffing, etc.) institution.

(c) National sentiment enters into all these arrangements. No scheme will succeed in the face of maternal desire for the welfare of the child unless it inspires confidence in the woman who is being separated from her child.

(d) Where a mother with a child and who is a closed case, desires admission to a settlement, I favour her admission with the child, to live in a special reserve or institution associated $w$ ith the settiement as referred to under $(b)$ above.

As regards (a) (b) (c) and (d) above, I write out of my direct experience. I have found grave difficulties attaching to any arrangements for bringing up unweaned children apart from their mothers, not least of which is the dislike of a mother for her child being cared for by another. On the other hand, the policy of allowing closed cases to retain their children so far (over a period of 4 years) has appeared to justify itseli. 
By Dr. T. F. Davey, Medical Superintendent, L.cprosarium Uzuakoli, S.E. Nigeria.

It is generally agreed that leprosy is maintained in a community principally through those who have had intimate contact with sufferers from the disease. The children of patients are undoubtedl the most important agent $m$ this respect, and the reduction to a minimum of infections derived from leprous parents must therefore be one of the main objectives of leprosy control.

In order to form some estimate of what this implies in the ()werri I'rovince of Nigeria, an attempt has been made by working through patients attending leprosy clinics to discover the actual numbers of chil/ren involved. l'articulars have been obtained of no less than 3,031 uninfected children of leprous parents, and these are analysed in the following taliles.

TABLE I. Numbers of Uninfected Children by Age Groups. A(;E (iROUPS ()F CHILIREN.

\begin{tabular}{|c|c|c|c|c|c|c|c|c|c|}
\hline Age & $0-2$ & $3-4$ & $5-6$ & $7-8$ & $9-10$ & $11-12$ & $13-14$ & I5-I6 & Total \\
\hline $\begin{array}{l}\text { patient } \\
\text { Liviug away }\end{array}$ & f(0.) & .157 & 358 & 327 & 2.1 .4 & 117 & +4 & 34 & 1,985 \\
\hline from patient & 62 & 168 & 200 & 171 & 206 & 1.10 & 65 & $3 . t$ & $1,0.96$ \\
\hline otal & .60 & 625 & $55^{8}$ & .198 & 450 & 257 & 100 & 68 & $3,03 \mathrm{r}$ \\
\hline
\end{tabular}

TABLE II. Same Children in different age groups, according to type of leprosy from which parent is suffering. AGE GROUPS OF CHILDREN.

Type of leprosy

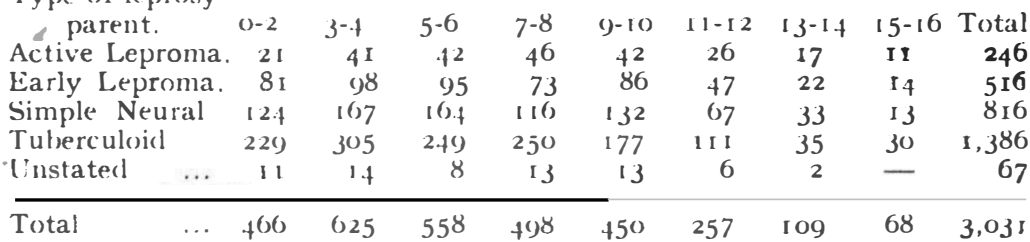

Table If. gives the complete picture. A more accurate estimate of the immediate problem is provided by Table III. which limits the analysis to cases where the child is now living with the leprous parent.

TABLE III. Children actually living with infected parent, analysed as in Table II.

Type of leprosy AGE GROIPS ()F CIIIII)REN.

\begin{tabular}{|c|c|c|c|c|c|c|c|c|c|}
\hline of parent & 0.2 & $3-4$ & $5-6$ & $7-8$ & $9-10$ & 1 I -12 & $13-14$ & I 5-I6 & Tot: \\
\hline Active I,eproma & 20 & 27 & 18 & 22 & 17 & II & 8 & 5 & \\
\hline rly Leproma. & 65 & 56 & .18 & 30 & 37 & 18 & 4 & 3 & \\
\hline e Neural & 107 & 124 & 110 & 93 & 80 & 44 & 15 & 3 & \\
\hline uloid & $20 \mathrm{I}$ & 240 & 178 & 173 & 104 & 41 & 17 & 23 & \\
\hline stated $\quad \ldots$ & II & ro & t & 9 & 6 & 3 & - & - & \\
\hline & 404 & 457 & $35^{8}$ & 327 & 244 & 117 & 44 & 34 & \\
\hline
\end{tabular}


The first two horizontal columns of Table 1II. contain the most significant figures, and in Table IV. an analysis is given of the 389 children concerned, indicating the sex of the infected parent in each case.

TABLE IV. Sex of infectious parents (Lepromatous cases). ACIE GROUPS OF CHILDIREN IIVIN( WITH PARENT.

\begin{tabular}{lcccccccccc} 
Infected parent & $0-2$ & $3-4$ & $5-6$ & $7-8$ & $9-10$ & II-I2 & I3-14 & $15-16$ & Total \\
Mother & $\ldots$ & 46 & $5 \mathrm{I}$ & 31 & 33 & 25 & -13 & 4 & 5 & 208 \\
Father & $\ldots$ & 39 & 32 & 35 & 19 & 29 & 16 & 8 & 3 & 181 \\
\hline Totals & $\ldots$ & 85 & 83 & 66 & 52 & 5.1 & 29 & 12 & 8 & 389
\end{tabular}

These figures indicate a formidable public health problen. It is estimated that the numbers of patients attending leprosy Clinics $(14,071$ when the enquiry was initiated) represent approximately one-fifth of the total number of people infected with lejprosy in the Province, and therefore in order to obtain a realistic: estimate of the magnitude of the problem, it is necessary to multiply the above figures by five. There are probably 15,000 uninfected children of leprous parents at the present time in the Province.

The leprosy contro! programme being undertaken consists in treating the problem clan by clan, its essence being the voluntary segregation of all open cases in model villages in each clan locality. Free treatment is provided locally at the leprosy clinic for all patients, and none but members of that particular, clan may attent the clinic or live in the village. A survey of the clan by Centrat Staff and preventive workers known as leeprosy Inspectors leads to leprosy control, and this is followed up by propaganda, repeated surveys, and the observation of contacts. Welfare workers who care for the wellbeing of segregated patients and investigate then. family problems now play an important part in the programme, and between the leprosy Inspector and the Welfare ()fficer all cases of uninfected children can be investigated.

In the light of the above statistics, the need for vigorous preventive work among uninfected children is apparent. Some form of institution both for infants and o!der children is inevit. able, and the following considerations arise.

1. Preventive work among uninfected children must be on a large scale. A crèche caring for 20 children or so is quite un. related to the actual need.

2. This immediately introduces the problem of finance. Cow's milk is unobtainable. Powdered and tinned milks are costly.

3. The large staff required also represents a serious problem. In Nigeria, the upbringing of young children away from their mothers calls for devotion and skill if a high mortality is to be avoided, and a relatively large number of nurses is essential. 
Where the children of lepers are concerned additional problems arise. In this I'rovince it is extremely difficult to find healthy nurses who are prepared to give the affection and personal carewithout which the survival of the children is unlikely. The traditional attitude to leprosy dies hard. We have proved that a child who has already had contact with its leprous mother will not be. acceptable to the nurses.

The policy being pursuerl attempts to adopt a realistic attitude to these problems, while working at a financial level related to that governing leprosy control work in Nigeria.

It is considered unnecessary to isolate all uninfected children from their parents in children's home, the general principle being to leave the children of closed cases with their parents, but under observation, and to make suitable provision for the children of open cases. 'These latter can be divided into two groups :

(1) Unweaned childreı.

(2) Weaned childreı.

1. Univeaned Children of Open Cases.

This group presents the greatest problem. Isolation of the infants from their mothers is necessary. From Table IV. it will be observed that the actual number needing immediate attention is 46. The policy adopted is to encourage the mothers to come to the Central Settlement before delivery, and have their confinement under controlled conditions. Subsequent procedure depends on the state of the mother's health. If she is regarded as highly ir. fectious and nursing the child is likely to be inimical to her own health, there is no alternative to removing the child forthwith to a crèche of standard type where the child is reared on artificial foods entirely isolated from the mother. Nurses at this crèche are invariably ex-patients. The crèche need only be small. It also caters for orphaned infants of. leprous mothers. Strict supervision by an experienced and highly qualified matron is essential.

Where milk and nipple are bacteriologically negative, and the general health of the mother is good, a simpler and more economical procedure is adopted. The child is transferred to a distinct department, the "Nursery," where suckling is permitted under strict control. The department has the following features :-

1. Children are isolated from their mothers, who are quartered a satisfactory distance away, but are allowed to attend ancl feed the children, a strict no-contact technique being adopted.

2. The nurses are themselves patients, closed cases suffering from inactive neural leprosy, lepromin positive, and soon liable for discharge. These live in separate quarters in the Settlement, but 
when coming on duty have to bathe and change into special gar. ments which are not removed from the department.

3. Regular examination of mothers, nurses and children is essential.

This is regarded as the main department, and in principle it has the following practical advantages over the crèche :-

(a) It is largely independent of artificial feeding and its problems.

(b) By the use of paticnt nurses, the problem of caring for infants who have already had contact with their mothers is overcome.

(c) Having sufferel themselves, such nurses are likely to exhibit the care and devotion necessary.

(d) It can be applied on a large scale.

(e) It is financially economical, both in materials and staff; for the nurses are recciving treatment, and are satisfied with maintenance allowances rather than a salary.

Again strict supervision is necessary.

These arrangements are of course not ideal, but they afford the only practical means of tackling the problem on the scale which it demands.

2. Weanlis Childien of Open Cases.

When weaned, it is the policy to send all children to the care of healthy relatives, and subject them to periodic examination by Leprosy Inspectors.

Unfortunately circumstances arise where it is impossible in carry out this policy, as in the following cases:-

(a) Cases where no relatives are available to care for the children.

(b) Orphans of leper parents.

(c) Cases where, on account of the death of its parents, an open case becomes responsible for a child not his own, but closely related to him. There are many instances where a responsibility of this type is hindering a patient from being segre ated as healthy children are strictly excluded from segregated villages.

For these exceptional cases, a Preventorium is necessary. Staffed by ex-patients, this is a home where children can be cared for up to the age of 14 , receiving education and trade training. It is situated outside the Central Settlement, but is in allow for adequate supervsion.

3. Unweanied Childien of Closien Casis.

Mothers who are closed cases and are suffering from favour. able types of leprosy are instructed to continue living at home with 
their children. They are not allowed to be segregated with open cases in villages, settlements, etc. Arrangements are made for the periodic examination of both mother and child. The mother is expected to attend for treatment at the local clinic, and cases of alleged hardship are investigated by welfare worker

These arrangements cover the vast majority of such cases, but circumstances arise where the mother is unable to maintain herself, being either (leformed or a pauper, and it is necessary for assistance to be given to such cases. For these people a Mothers' Home is provided at the Central Settlement, away from the living (quarters of other patients, where the mothers, while able to receive leprosy treatment, are isolated with their children from open cases. The department is small.

\section{Weaned Children of Closed Cases.}

These live at home, either with their parents or with healthy relatives, and no snecial provision is necessary.

Child-Whlfarl: ()rganisation

In order to carry out the policy described, it is necessary to have an effective child-welfare organisation to obtain the necessary information, maintain records up to date, and provide material for the different children's homes which are under its control. The organisation of the I)epartment of Child-Welfare at $U^{2}$ zuakoli is as follows :-

\section{A. The Central Office.}

Functions :

1. A register of pregnant patients is kept $u$ ) to date.

2. Cas shcets for all uninfected children are filed and periodic examinations recorded.

3. The preparation of waiting lists for the different children's homes.

4. The organisation of periodic examinations of children. mothers, nurses, etc.

5. The collation of monthly returns from outstations.

6. The organisation of propaganda.

\section{B. Outstation work.}

This is carried out by I.eprosy Inspectors and weltare workers. A monthly report must be submitted to the Central Office giving the following information :- .

(a) Patients reporting as pregnant.

(b) Particulars of children born to patients.

(c) Particulars of children for whom patients have become responsible. 
(d) Information regarding the uninfected children of new patients.

Reports of the examinations of uniniected children must be sent to the child-weliare officer in charge of the Central Office who is himself liable to tour and investivate matters relating to the (lepartment.

The investigation of cases of alleged hardship) and difficulty is an essential part of the local organisation.

\section{Children's Homes.}

firom the foregoing it will be seen that four homes are neces. sary.

(1) The (reche, where infants of highly infectious cases are isolated from birth and reared on artificial foods. A small department.

(2) The Nursery, where infants of open cases are isolated from their mothers, but these are allowed to suckle them under controlled conditions. A large department.

(3) The Preventorium, for the accommodation of weaned children where there are no suitable healthy relatives to care for them.

(4) The Mothers Home, a smali department where closed cases live with their infants, admission being limited to those mothers who by reason of poverty or deformity are unable to maintain themselves at home.

The practical operation of the complete department is still in its early stages. The Central Office is working effectively and is responsible for pbtaining the information given $i n$ the tables. The outstation work is operating in many areas, but the effective development of the series of children's homes is dependent on the provision of the skilled sujervision which is absolutely essential. The duplication of the series of homes in another part of the Province will allow the majority of cases needing isolation in them to be dealt with effectively.

In preventive work among uninfected children the interdependence of the public health and the social welfare aspects of leprosy contro! work is admirably illustrated. The solution of family difficulties by sympathetic welfare work, the creation of the right attitude on the part of nurses, the co-operation of patients everywhere, these are essential elements in achieving what must be regarded as a most important aspect of the public health.

My thanks are due to the Honourable the Director of Medical Services for permission for the publication of this article. 


\section{By I)r. Chas. M. Ross, Uzuakoli leepar Settlement, S.E. Nigiria.}

P'reventoria for all children of leper parents are not necessary. For the new-born children of infectious parents preventoria are absolutelv essential, but if the mother is non-infectious and is segregated from all infectous cases the child can be allowed if necessary to remain with the mother until it is weaned. We think, however, that preventoria for children once they are weaned are to be avoi led, and we also think that the sooner the child is weaued and marle to live in the native village the better.

Apart from leprosy work we have known several orphari African children over a considerable number of years who have been looke! after from birth in homes or institutions controlled by luropeans. We have seen in such cases a high incidence of sick. ness, general unfitness to resume life in their normal Africa surroundings and, in after life, inability to find employment and assume responsibility for themselves. These children seem to lose their indepentence and become entirely dependent on those who have been their guardians.

We have known three boys whose cases illustrate this particularly well. (Jine of them when he went to a boarding school was a constant source of worry and trouble to his guardian. He was unable to cook his food properly and fend for himself in school life; his guardian har! to keep him supplied with food and other things which he could easily have obtained for himself if he had been accustomed to do so in his home town. The boy managed after a prolonged time at school to reach Standard VI, but for a considerable time could not settle down and seemed unable to find employment. ()f the other two boys the first must be now about 16 years of age; he was far outdistanced by his fellow schoolmates and after many years at school failed to pass into Standard I. He seems to have lost all natural independence. The second boy is younger but seems to be entirely in the same condition.

In rigeria we have found a willingness in the relatives to look after the children of lepers who have been weaned in the crèche. From the crèche weaned children have been taken by relatives and, on their return for inspection, we have found them well nourished and healthy, some perhaps even more so than when they left us. If the Africans think we are willing to feed and educate the children they are very pleased to let us do so. Many of them would welcome our taking over this responsibility and a condition such as the following may result. A child had been supported many years as his father, who was a leper, was unable to look after him. When there was a possibility that the 
father would soon be discharged he was told he could lake his sori with him. The father was very indignant and said he was no longer responsible for his son's feeding and eclucation; the boy must be fed, clotherl and educated by the people who looked after him from birth, and they must also be ready to help) him all the days of his life.

In our opinion all children of leper parents should be removed to a crèche or preventorium at birth, unless the parents are non.infectious and the child can be segregated in such a way that there is no possibility of exposure to infection. We also think that all children should be weaned as soon as possible and removed from the colony or preventorium so that they caln learn to adjust themselves in normal African surroundings and circumstances.

\section{By Dr. L. H. Wharton, Mahaica Leprosy llaspital, British Guiana.}

In I3ritish Guiana the problem of clealing with the children of leprous parents is not a difficult one. The leprosarium at Mahaica has 360 patients, of which only one-haif are infectious cases. Although the sexes are lodged in separate compounds segregation is not absolute and births lo occur, the average birth rate being 2 per year for the past 5 years. Each of these infants is given to a near relative or guardian as soon as possible after birth, usually within 7 days. Government gives an allowance of $£ 10$ s. 10d. per month to the guardian until the patient is discharged: There has never been any difficulty in obtaining guardians for these chiidren, even before the days of allowances. The children are cxamined every six months until they are 14. Most of the births in the institution occur among the 600 discharged patients. When these are due for confinement they return to the I.cprosarium; they will not enter a general hospital on account of social stigma. Of these, four is the annual average for the last five years. The mothers leave the leprosarium as soon as they recover from the confinement, taking their children with them. As in the case of the in-patient's children, these are examined every six months till they are 14 years old.

As the number of these children is so small, and as the present system is working satisfactorily, there is no need in British Guiana to erect a Preventorium for this purpose.

\section{By Dr. Robert Cochrane, Hon. Director, Leprosy Campaign, Madras Presidency, India.}

The importance of child leprosy camnot be over-emphasised, but as far as India is concerned it is frequently forgotten that a 
great deal of child leprosy is comparatively innocuous. A study of figures over the past eight years at the Silver Jubilec Children's (linic, Saidapet, indicates that there is a tendency to spontaneous disàpearance of neural lesion in childhood, and that af all chil.. dren who ac quire leprosy less than $50 \%$ progress to the more serious forms. By serious form is meant those cases which no: only become lepromatous but which become mutilated. Therefore child leprosy must be looked upon in the light of that type which is scrious. A further study inclicates that about $7 \%$ of simple macular lesions in children become lepromatous in later life, and in all probability nearly a $100 \%$ of the incipient or pre-leprona. tous-Muir's Juvenile l.eprosy-(levelop into leproma in later life. The greatest factor in the development of lepromatous leprosy is intimate and continuous contact with an open case. In countries such as South Africa, Brazil, etc., great emphasis is laid on the separation of healthy children from infective parents, but in this country, owing to the faci that it is impossible compulsorily to segregate all infective cases and because, in most areas in India, nearly all children can be found a home, it is probably a better policy to bring up children in their own environment rather than in the artificial environment of a healthy children's home. For, if they are placedl in such an institution, they become divorced from the life of their community and are liable to become institutionally-minded with the resultant problems which tend to arise in children who have become homeless. Nevertheless, it is a fundamental axiom that the child of parents with infective leprosy should be separated, preferably at birth and certainly at as early an age as possible, from the infective parent or parents. It is sometimes more practicable to remove the source of infection to an isolation centre than remove the child, and in India this frequently can be done, for there are usually relatives able to care for the child. While the segregation of healthy children of parents with leprosy has been rightly stressed, it must be remembered that possibly as many children acquirc leprosy from relatives other than parents. Let me not be misunderstood, there is great scope for Healthy Children's Homes, but before sending a child to one every effort should first be made to remove the source of infection rather than the child, then if this cannot be accomplished the child must be separated from the infective person in a suitable home. Space does not permit me to enlarge on this subject, but to undertake such work means considering the question not only of the child of school age, but the infant which must be cared for in a crèche, the toddler and the young adolescent. This is a problem of much complexity and should be handled by a specially trained 
personnel. Questions such as re-absorption into the community, marriage and training for a career, professional or otherwise, all have to be considered in the setting up of a special institutions for healthy children of parents with leprosy. Therefore the whole. tendency of the policy in Madras has becn to concentrate on children with leprosy and the infective parent rather than healthy children. The post-war reconstruction plan envisages the development of children's sanatoria and the prevention of leprosy in urban and rural listricts. There is evidence to show that if children are sejparated from night contact with an open case in villages there is a fair chance of leprosy control being effected. The following table gives evidence from the Rural I revention Unit 23 miles from Chingleput.

\begin{tabular}{|c|c|c|c|c|c|c|c|c|c|}
\hline Village & $\begin{array}{l}\text { Gross } \\
\text { inci- } \\
\text { dence }\end{array}$ & $\begin{array}{l}\text { I939 } \\
\text { Open } \\
\text { case } \\
\text { rate }\end{array}$ & $\begin{array}{l}\text { Child } \\
\text { rate }\end{array}$ & $\begin{array}{l}\text { (iross } \\
\text { inci- } \\
\text { dence }\end{array}$ & $\begin{array}{c}194^{2} \\
\text { - Open } \\
\text { case } \\
\text { rate }\end{array}$ & $\begin{array}{l}\text { Child } \\
\text { rate }\end{array}$ & $\begin{array}{l}\text { (iros } \\
\text { inci- } \\
\text { lence }\end{array}$ & $\begin{array}{c}\text { 1945 } \\
\text { Open } \\
\text { case } \\
\text { rate }\end{array}$ & $\begin{array}{l}\text { Child } \\
\text { rate }\end{array}$ \\
\hline *Polambak & $\mathrm{ram}$ & & & & & & & & \\
\hline $\begin{array}{l}\text { village } \\
\text { * Polambak }\end{array}$ & $\begin{array}{l}42.52 \\
\mathrm{sam}\end{array}$ & 25.80 & 32.60 & 52.89 & 23.25 & $25 \cdot 5^{8}$ & 44.13 & 20.87 & $9 \cdot 37$ \\
\hline $\begin{array}{l}\text { cheri } \\
\text { *Perambak }\end{array}$ & $\begin{array}{l}45.55 \\
\mathrm{cam}\end{array}$ & 23.80 & 19.05 & 74.00 & 13.63 & 13.63 & $3^{8.79}$ & I6.66 & 16.66 \\
\hline $\begin{array}{l}\text { village } \\
\text { * Perambak }\end{array}$ & $\begin{array}{l}38.4^{6} \\
\mathrm{ram}\end{array}$ & 28.57 & 14.28 & $3^{8.64}$ & 31.25 & I8. 75 & 30.95 & 15.38 & I 5.38 \\
\hline $\begin{array}{l}\text { cheri } \\
\text { Muluvana }\end{array}$ & $\begin{array}{l}78.12 \\
\text { karanai }\end{array}$ & $30.0 \%$ & $50.0 \%$ & 60.60 & 37.50 & $50.0 \%$ & 67.16 & 22.22 & 22.22 \\
\hline $\begin{array}{l}\text { village } \\
\text { Muluvana }\end{array}$ & $\begin{array}{c}33.12 \\
\text { karanai }\end{array}$ & $45 \cdot 45$ & 18.18 & 48.41 & 29.41 & 23.53 & 70.65 & 19.23 & 23.08 \\
\hline cheri & 29.12 & $50 \%$ & $50 \%$ & 50.33 & 30.77 & $38.4^{6}$ & 49.79 & $25 \%$ & $25 \%$ \\
\hline
\end{tabular}

It will be noted that there has been a general reduction of the incidence of leprosy in three out of the four villages in which night segregation has been enforced. The only exception is Perambakam village where the incidence has apjarently increased siightly. It is of interest to note that I'erambakam village only began to take night segregation measures scriously after the year 1944. A further point of interest is the marked (lrop in the child rate in Polambakam village between 1939 and 1945. It will be noted that the open case rate has decreased while the gross incidence has increased, this may be due to the fact that some open cases have died and others left the village and the time interval may not be long enough for fresh open cases to have developed. The open case rate has decreased in all four villages during the past five years, in two of them very markedly. On the other hand in the two villages not under night segregation the incidence of leprosy in one of them is more than doubled, and in the other more than $1 \frac{1}{2}$ times the incidence in 1939. Both these villages have shown a steady increase in the incidence of the disease during the past five years. The open case rate has also decreased in these two villages 
owing to the death of a number of open cases and again the time interval for the development of fresh open cases may not as yet be sufficient. While no definite conclusions can be drawn, we feel that the over-all picture shows a downward trend indicating a possible favourable turn in the epidemic of leprosy in these villages and encourages the pursuance of this experiment.

While the principle is accepted that no child should be allowed to come into contact with an open casc, be it a parent, a relative or a co-tenant, except under special circumstances, preventoria envisaged in Brazil are not recommended in south India, largely because children can be iooked after in their own homes and because as a result of the joint family system it is not only the child of the infective case but all children within the household who are liable to infection. Great emphasis is being laid on the starting of sanatoria for chldren with leprosy and especially with the type which is liable to become lepromatous. Owing to the fact that many lesions of neural leprosy are benign and non-progressive, children with such lesions, provided they are not in contact with open cases, will be observed under natural conditions rather than admitted into leprosy Sanatoria.

A new venture is being inalugurated under the auspices of the Kasturba Ciandhi Fund-a fund to commemorate the life and work of Gandhiji's wife. A home for women and children suffering from leprosy is to be opened on the South Arcot District of this Presidency and this work will be integrated with the whole pre. ventive work of that district.

Urban leprosy is a more difficult problem than rural leprosy, and propaganda is being organised so that the open cases shall gradually realise the seriousness of coming into contact with healthy people especally children, and, where facilities are avait. able and open cases refuse to segregate themselves or cannot segregate themselves, then legal measures will be adopted to force such segregation at least in the Madras Presidency. It is my firm belief that if night contact with children was prevented the epidemic of leprosy would come under control. I believe that the number of adults who get leprosy is so small that if children were prevented from getting the disease leprosy would gradually die out of India.

*By Dr. John Loze, Leprosy Research Department, School of Tropical Medicine, Calcutta.

In recent years increasing stress has been laid on the protection

*Reprinted from Lcprosy' in India, 1942, Vol. 14, p. 98. 
of children from leprous infection by early and efficient separation of children from infectious contact with their parents and others. Leprosy is not hereditary and children separated from infectious contact at birth, and brought up in healthy surroundings almost invariably remain free trom leprosy. The separation of children from infectious contact at birth is therefore the ideal policy, and is sometimes practised.

Often, however, even in leprosy institutions, it is found difficult or impossible to carry out this policy, particularly in countries where artificial feeding of infants is little understood or practised. In some leprosy institutions, therefore, a compromise has been made. Mothers have been allowed to keep) and suckle their children for a time until they are considered old enough for separation. The time that the mother has been allowed to keep the child has varied fairly widely between a few weeks or months and two years, but experience has shown that the longer the child is kept in infectious contact the greater is the risk to the child.

The problem has been rendered more difficult by the fact that in some leprosy institutions marriage and married life have been allowed, although in India in recent years married life in many leprosy institutions has been definitely disallowed, and where allowed it is usually contined to old married couples, and not permitted to new admissions.

A few months ago the writer paid a visit to a leprosy institution in India in which until a few years ago the policy was to allow marriage and to leave any children with the parents in the institution until the age of 18 months and then to remove them to a Healthy Children's Home. Juring this 18 months they have been in contact not only with the mother, who might not have been infectious, but also with other patients some of whom would be infectious. A considerable number of these children have later developed the signs of leprosy and have had to be removed to the L.eper Children's Home adjoining the institution. There were twenty-five such children in the I-eper Children's Home at the time of my visit. It was thought worth while to get the details regarding these twenty-five children showing signs of leprosy. These details are given below.

It is impossible on the data available to give any accurate idea of the incidence of leprosy in children separated from infectious contact at the age of 18 months. The data presented below relate only to those who have developed leprosy, and it is not known how many similar children did not develop leprosy. evertheless certain conclusions from these data are justified, namely, that the separation of children from infectious contact in the institution has 
been done too late or too incompletely, or both, to prevent the development of leprosy in a considerable proportion of the children.

(CHILIDREN BURN INSIDE THE ASYLUM.

Age of separation I Jate and age at which signs

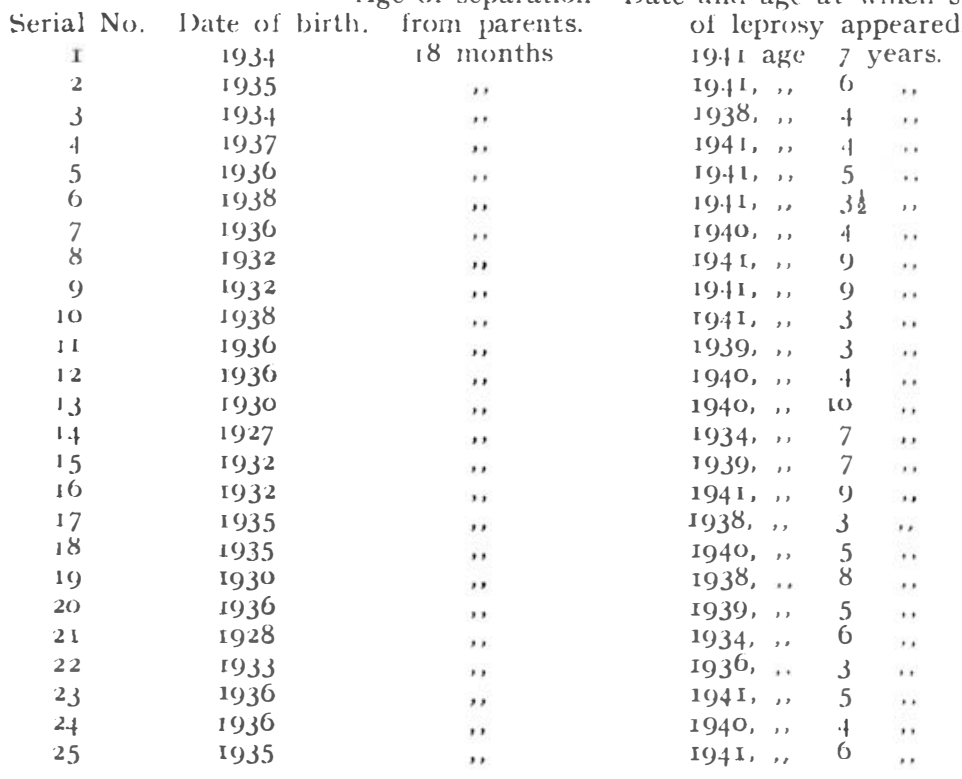

I am informed that steps have been taken in the institution in question to remedy this state of things and that married life is reduced to a minimum and is confined almost entirely to women beyond the age of child bearing, and that separation of children is now carried out earlier and more effectively.

There are, however, even now a few leprosy institutions in India in which the state of things is far less satisfactory, and it is a warning to these institutions that this note is published. Married life such as may produce children should not be allowed.

In institutions where married life is not entirely disallowed, children should be removed as early as possib?e, not later than six months. Jouring the first few months of life before separation, contacts in the institution should be kept at the very minimum necessary in the interests of the child. If the mother herself is an infectious case, the periods of contact should be contined to the actual periods of breast fecling, and during breast feeding the physical contact should be recluced to a minimum by suitable clean cloths used by both mother and child. If the mother is not an infectious case, these precautions may not be necessary, but great care is needed to prevent contact between the child and other patients who are infectious. 
l'robably the be $t$ interests of the child are best served by arranging for the child's aloption possibly by healthy relatives, and the complete removal of the child from the neighbourhood of the institution. If this is impossible, a crèche under a skilled nurse should be provided to look after such children and maintain separation f:om the parents and also other patients. 